\title{
Eigenartige Ausnutzung einer mißlungenen plastischen Operation.
}

\section{Von Dr. J. F. S. Esser,}

Fachärztlicher Beirat beim Gardekorps und Spezialarzt für plastische Chirurgie an den Kliniken der Geheimräte August Bier und Kr ü ckmann in Berlin..

Füsilier S. wurde mir aus Breslau zur Operation zugeschickt. Durch Schußverletzung war der größere Teil der Oberlippe, ein kleiner Teil des linken und ein großer des rechten Nasenflügels zerstört (s. Fig. 1).

Fig. 1.

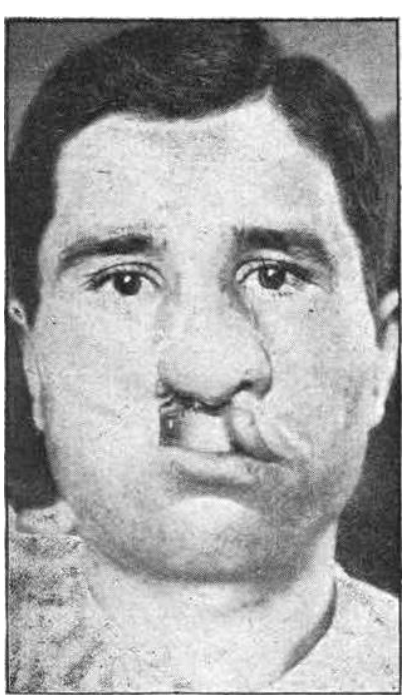
Der anderweitig vorgenommene Versuch, aus einem gestielten Halslappen die Oberlippe wieder herzustellen, war nicht gelungen, $\dot{d}$. $h$. das Lappenende war zum größten Teil nekrotisiert (s. Fig. 2 u. 3), nur der Stiel war neben der Unterlippe noch vorhanden, aber sehr zusammengeschrumpft und fest vernarbt, und an Stelle der Oberlippe befand sich eine große Narbe. Ich gebe mir immer große Mübe, jede voraufgegangene $O$ peration aus. zunützen, auch in solchen Fällen, wo man mit einer ganz neuen Operation viel leichter auskommen würde. Der Hauptgrund hierfür ist, daß bei dem Patienten nicht die Ueberzeugung unterstützt wird, daß die Operation völlig mißlungen ist und dadurch das Vertrauen zu dem Arzte geschädigt wird.

Fig. Nr. 2 u. 3 zeigen den $\mathrm{Pa}$ tienten, ajs er in meine Behandlung kam. Ich entschloß mich, das Material des Stieles wie eine Schlange fortkriechen zu lassen, bis es soweit in die Oberlippe gekommen war, um dort verarbeitet werden zu können. In verschiedenen Sitzungen wurden dazu abwechselnd die vordere Hälfte oder hintere Hälfte des Stieles lospräpariert und zu dem Defekte hin verschoben und dort in

Fig. 2.

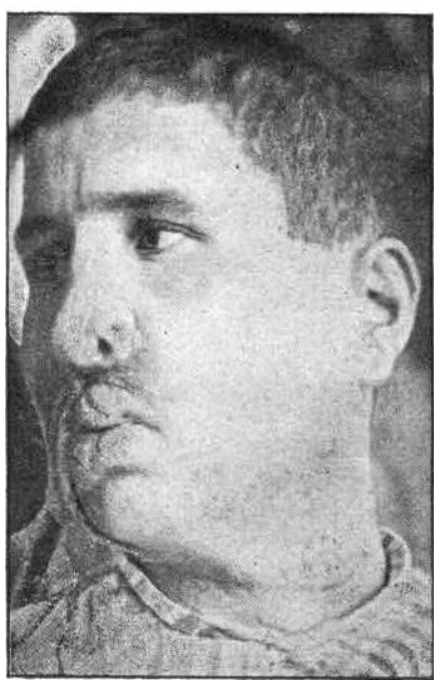

Fig $\cdot 3$.

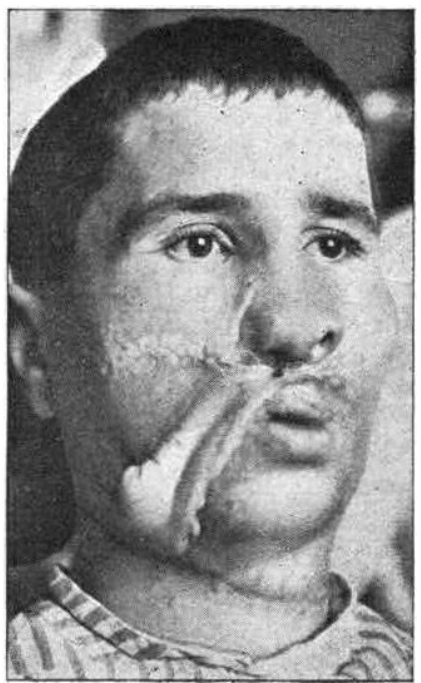


Fig. 4

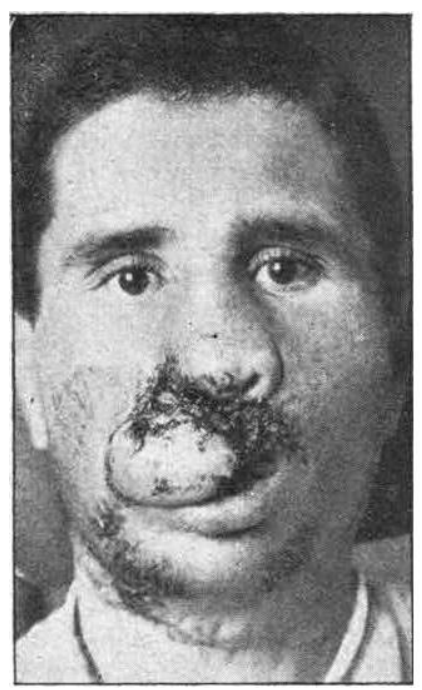

Fig. 5.

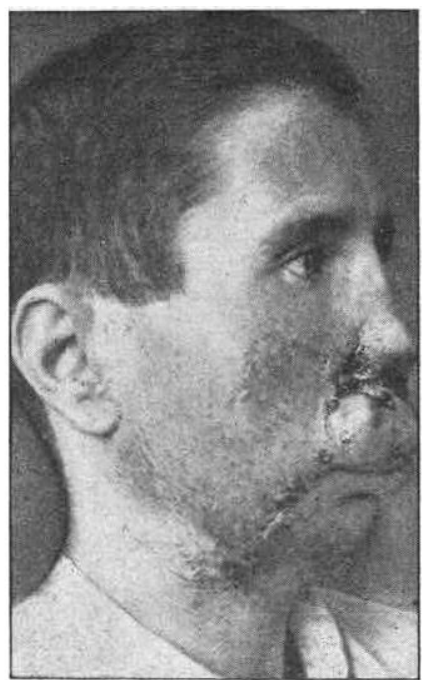

eine frisch gesetzte Wunde eingenäht. Bei Fortkriechen der unteren Hälfte des Stieles wurde immer der zurückgelassene Defekt zu einer vertikalen Nahtlinie zusammengenäht.

Fig. 6.

Fig. ?.
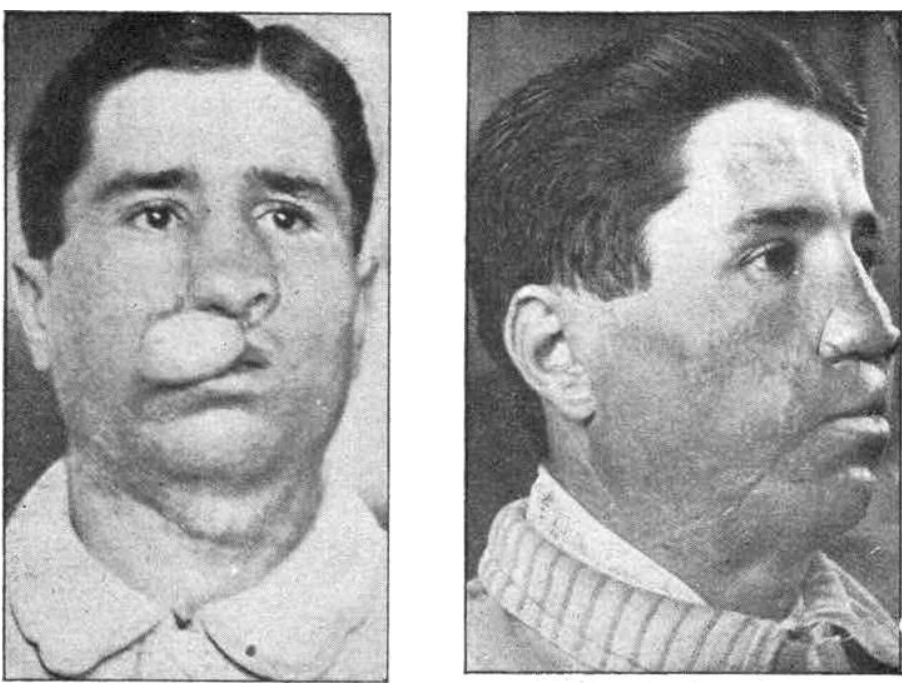

Nach und nach wurde die Situation von Fig. 4,5 u, 6 geschaffen und nach einer modellierenden Korrektur war die Lippe fast normal, wie die Fig. 7,8 u. 9 deutlich angeben. Die Korrektur der Nase war

Fig. 8 .

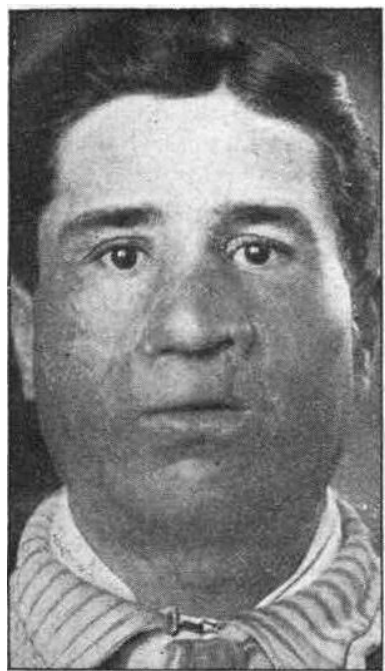

Fig. 9

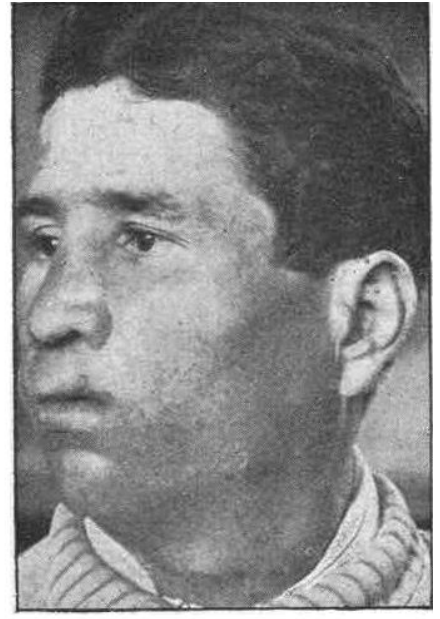

eine Sache für sich, welche ich hier nicht eingehenc 5 twickeln werde. Nur sei gemeldet, daß das Hautskelett, das Hautseptum und auch die Nasenflügel fast normal gestaltet wurden. 